IJMS 2019 vol. 6 (1): 7 - 19

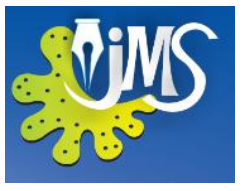

\title{
Reduplication: Its Types and Functions in Sinhala
}

\author{
Lalith Ananda M.G. \\ Department of English and Linguistics, University of Sri Jayewardenepura \\ Sri Lanka
}

\begin{abstract}
Reduplication can be largely viewed as a subtype of repetition, a pervasive phenomenon of every language affecting all types of linguistic units such as sounds, words, and phrases. It can be also viewed as the systematic repetition of phonological material within a word for semantic or grammatical purposes. The aim of the present paper is to examine reduplication phenomenon in Sinhala ${ }^{1}$ in the broader spectrum of reduplication patterns and functions evidenced in many languages of the world. Data for the present study consisted of sentences with reduplication types and functions that can be distinguished in Sinhala. A sample of 60 sentences with such reduplication were used. The researcher consulted 05 adult native speakers of Sinhala for their grammaticality judgments about those sentences. The examples and example sentences used in this study are the data used for this purpose. In terms of the main findings of the study, it can be concluded that Sinhala employs reduplication in both of its spoken and written varieties in varying degrees and for various effects. In its written form, reduplication fulfills some stylistic functions and is mostly manifested in poetry, riddles, songs, anecdotes and narrations. The colloquial Sinhala uses reduplication in ordinary discourse and can be seen irrespective of the dialectal varieties. It can be observed at phonological, morphological/morpho-syntactic, and lexical levels. Sinhala manifests reduplication over a broad range of categories such as noun, verb, adjective, and adverb. Nevertheless, Sinhala is quite impoverished when viewed against the broader spectrum of reduplication types, sub-types, functions, and even in the areas of language affected by reduplication as evidenced in many languages of the world.
\end{abstract}

KEYWORDS: reduplication, full, partial

\footnotetext{
${ }^{1}$ Indo Aryan, pro-drop, diglossic, spoken by majority Sinhalese in Sri Lanka.
} 


\section{INTRODUCTION}

Reduplication can be largely viewed as a subtype of repetition, a pervasive phenomenon of every language affecting all types of linguistic units such as sounds, words, and phrases. Reduplication is a formal operation whereby part of the base or the complete base is copied and attached to the base (Haspelmath 2002: 24). Reduplication typically yields aspectual meanings such as continuative, frequentative, habitual, imperfective, intransitive, iterative, or progressive (Moravcsik 1978; 151). It generally subsumes three main areas: the process, the result (new word), and the element repeated. As defined in Carl Rubino (2005), reduplication is the systematic repetition of phonological material within a word for semantic or grammatical purposes (Rubino 2005, 11). As Carl Rubino (2005) observes, reduplication is very common throughout Austronesia (Pacific Islands, Philippines, Indonesia, Madagascar), Australia, South Asia, and many parts of Africa, the Caucasus, and Amazonia. In the Western Hemisphere, some language families are particularly amenable to reduplication, Salishan, Pomoan, Uto-Aztecan, Algonkian, Yuman, Sahaptian, Siouan, etc. (Carl Rubino, 2005, 11-30). Reduplication is equally diverse with respect to the semantic and grammatical functions it fulfills.

Generally, two broad types of reduplication are distinguished, depending on the size of the reduplicant: full vs. partial reduplication. Full reduplication refers to the repetition of the entire word, word stem (root with one or more affixes), or root. The following examples illustrate this point.
(1) Nukuoro total reduplication.

$\begin{array}{llll}\text { gohu } & \begin{array}{l}\text { (dark) } \\ \text { (getting dark) }\end{array} & & \text { gohugohu } \\ \text { vai } & \text { (water) } & \\ & \text { (watery) } \\ & \text { (Carl Rubino, 2005, 14) }\end{array}$

Partial reduplication is manifested in a number of forms such as consonant gemination, vowel lengthening, or nearly complete copy of a base. Example (2)

(2) Nukuoro partial reduplication.

ludu (pick trees leisurely) > lludu (pick trees frantically)
gai (eat) > gagai (fish are biting) (Carl Rubino, 2005, 14)

The functions associated with reduplication are diverse. They range from total meaning change, word formation, marking of number (plurality, collectivity), marking of tense, aspect, attenuation, intensity, transitivity, conditionality, reciprocity, derivation of temporal adverbials etc. Some of these functions are illustrated below.

(3) Tausug, Austronesian, Philippines: total meaning change

$$
\begin{aligned}
& \text { laway (saliva) > laway-laway } \\
& \text { (land snail) }
\end{aligned}
$$

(4) Indonesian: word formation

$$
\underset{\text { (spy) }}{\operatorname{mata}} \text { (eye) > mata-mata }
$$

Alabama (USA) marks the temporary versus permanent distinction in verbal aspect with vowel lengthening (5). 
(5) loca (to be black/covered in suit) > looca (to be a black person)

Also, attenuation with germination (6)

(6) kasatka (cold) > kassatka (cool)

Plural formation in Papago (Uto-Aztecan, USA) (7)

(7) gogs (dog) > gogogs (dogs)

Plural formation from Adjectives (Hitchiti, Muskogean).

(8) cikti (thick (liquids) > cikciti (thick, plural)

To create lexical subclasses as in Ilocano to make comparative adjectives (9).

(9) dakkel (big) > dak-dakkel (bigger).

To intensify the meaning of an action (Arapesh, Papua New Guinea) (10).

(10) $\mathrm{Su}$ (touch/hold) > susu (touch all over)

To derive temporal adverbials from temporal nouns as in Indonesian (11).

(11) pagi (morning) > pagi-pagi (early in the morning).

Rubino, 2005, 11-30)

(Carl

To convey a diminutive interpretation, as in Sranan (12).

(12) ferfi 'to paint' $>$ ferfi- ferfi 'to paint a bit'

(Silvia

Kouwenberg and Darlene LaCharite, 2005, 533)

To extend the meaning /inclusive function.

Hindi:
(13) aam 'mango' > aam-vaam 'mangoes and such fruit'

Kannada:

(14) kannu 'eye' > kannu-ginnu 'eyes and so forth'

(Elinor Keane, 2005, 244)

The above examples do not constitute an exhaustive list of different forms and functions of reduplication that can be seen in many languages of the world. Some languages have further fine grained reduplicative patterns and functions as shown by Dixon (1998). Nevertheless, some valid generalizations can be derived from the above examples with respect to the diversity of reduplicative patterns, broader scope of functions covered by them, attestation of diverse language families which are even genetically remote from each other manifesting reduplication, the extent of word classes affected by reduplication, as not only nouns and verbs, but even adjectives, adverbial formation too can be seen as a result of reduplication, and the systematic nature of reduplication.

Sinhala employs reduplication in both spoken and written varieties in varying degrees and for various effects. In its written form, reduplication fulfills some stylistic functions and is mostly manifested in poetry, riddles, songs, anecdotes and narrations. The colloquial Sinhala uses reduplication in ordinary discourse and can be seen irrespective of the dialectal varieties. It can be observed at phonological, morphological/morpho-syntactic, and lexical levels. Sinhala manifests reduplication over a broad range of categories such as noun, verb, adjective, and adverb. As noted in other languages, in Sinhala too both 
complete and partial reduplication can be observed and the reduplicated element functions as a single lexical item. Thus, reduplication is a very important linguistic tool that contributes significantly to word formation and richness of the expressive power of language.

The aim of this paper is to examine reduplication phenomenon in Sinhala in the broader spectrum of reduplication patterns and functions evidenced in many languages of the world and provide an overview of reduplication in Sinhala. In particular, it seeks to answer the following research questions.

a) What are the reduplication types manifested in Sinhala?

b) What categories or linguistic elements are affected by this process? / In what areas of language is reduplication manifested?

c) What are the functions of reduplication?

d) Where does Sinhala fit in a typology of reduplication?

It is hoped that the study will contribute significantly to the body of empirical and theoretical literature related to reduplication phenomenon in Sinhala, notably in the absence of a well-articulated study in this area.

\section{Existing Literature on Reduplication}

Inkelas and Cheryl Zoll (2005) present a new model of reduplication - Morphological Doubling Theory (MDT) - where reduplication is viewed as the double (or multiple) occurrence of a morphological constituent meeting a particular morphosemantic description. Whereas in previous theories the reduplicant is treated as an abstract morpheme, RED, whose substance is provided by phonological copying (e.g. Marantz 1982, Steriade 1988) or correspondence (e.g. McCarthy and Prince 1995), in Morphological Doubling Theory, reduplicant and base are both generated by the morphology as part of a construction which also embodies semantic and phonological generalizations about the output of reduplication. They argue that the driving force in reduplication is identity at the morphosyntactic, not the phonological level. The main claim of MDT is that reduplication results when the morphology calls twice for a constituent of a given semantic description with possible phonological modification of either or both constituents. Thus they focus on morphological reduplication, a subtype of reduplication, namely grammatical doubling or duplication effects within words, as illustrated in 15-17.

(15) Hausa kira: 'call'
kik-kira:
(pluractional)

(16) Amele bala-do? 'to tear' iterative) bala-bulu-do? (irregular
(17) Warlpiri kamina
kamina-kamina (plural)
(Inkelas and Cheryl Zoll, 2005: 01)

As such, they pay more attention to word structure. One main criterion that distinguishes between the former phonological theories of reduplication and MDT is that whereas phonological copying serves a phonological purpose, morphological copying serves a morphological purpose either by being a word formation process itself or by enabling another word formation process to take place. 
Elinor Keane (2005) discusses phrasal reduplication and thus deviates from the frequently discussed full and partial reduplication involving single lexical items. Her main focus is echo-reduplication and she uses data from Bengali, Hindi, Kannada, and Tamil (South Asian languages) to outline a systematic differentiation of the constituents working as inputs for echoreduplications. The hypothesis she puts forward is that the typological difference might be attributed to the genealogy of the languages under scrutiny, with Indo-Aryan languages showing prosodic and Dravidian showing morphosyntactic bases. Thus she is developing a formal model of reduplication, dual description, which is based on assumptions from declarative phonology. This distinguishes between objects and their descriptions, with the descriptions acting as constraints upon the form of the object. Objects are represented as hierarchical structures made up of labelled nodes associated with one another by dominance and precedence relations. Keane proposes various general constraints to ensure the well-formedness of the structures, such as what kinds of nodes can immediately dominate other nodes.

Reijirou Shibasaki (2005) proposes with data from Japanese that the aspectual meanings associated with reduplication such as continuative, frequentative, habitual, imperfective, intransitive, iterative, or progressive have developed along an evolutionary pathway. In his diachronic perspective on reduplication, he claims that reduplications in Japanese have changed their original verbal properties from Old to Modern Japanese into adverbials, in the sense that they have changed from lexical verbs to adverbial constructions, and in particular, verbal reduplications have been strongly adverbialized in Modern Japanese. He explores how Japanese verbal reduplication functions in clauses and discourse at each synchronic stage and how this diachronic transition has occurred. He concludes that Japanese verbal reduplication

has followed a unidirectional path in the grammaticalization of verb into adverbial. Once a given reduplicative verb becomes adverbialized in meaning and function, it undergoes phonological change, i.e. sequential voicing, more often than not. He attempts to substantiate his claims with a quantitative analysis of Japanese texts from the past 1100 years.

Carl Rubino (2005) presents a general description of different types of reduplications and their functions in the languages of the world. He gives an overview of the semantic and grammatical functions reduplication may serve. With respect to form, Rubino highlights that two types can be seen based on the size of the reduplicant. They are full versus partial reduplication, where the former corresponds to the repetition of the entire word, word stem (root with one or more affixes), or root and the latter can take place as consonant gemination, vowel lengthening, or nearly complete copy of a base. As Rubino shows, the phonological nature of the reduplicated material varies from language to language and construction to construction. Reduplicative morphemes are often characterized by the number of phonemes included in the copy, C, CV, CVC, V, CVCV, etc., the number of syllables to be reduplicated, or the number of repeated morae. On another dimension, he identifies reduplicated constructions as simple, complex, and automatic. A simple construction is one in which the reduplicant 
matches the base from which it is copied without phoneme changes or additions. A complex construction involves reduplication with some different phonological material, such as a vowel or consonant change or addition, or phoneme order reversal. Automatic reduplication is reduplication that is obligatory in combination with another affix, and which does not add meaning by itself to the overall construction; the affix and reduplicated matter together are monomorphemic. As for functions of reduplication, Rubino concludes that they range from total meaning change, word formation, marking of number (plurality, collectivity), marking of tense, aspect, attenuation, intensity, transitivity, conditionality, reciprocity, derivation of temporal adverbials etc. With respect to the geographical distribution of reduplication, he shows that reduplication is a quite pervasive phenomenon as it can be found in several areas of the world that are genetically quite diverse, as can be seen in the Indian subcontinent where reduplication is evident in languages spanning several families.

As the above brief discussion indicates, existing literature on reduplication offers a number of theoretical standpoints and approaches, some of which complement each other, and can be largely subsumed under phonological and morphological approaches. According to some of these theoretical standpoints, the instances of reduplication can be viewed as a phonological process (Newman, 2000), morphological (Marantz, 1982), syntactic (Utz Maas, 2005), interaction between the phonological and morphological modules of grammar (Eric Raimy, 2000), transformational approach (Carrier, 1984), to name some of the most prominent. The present study does not attempt to analyze the Sinhala data in relation to a particular theoretical alignment mainly because such standpoints abound, and also the focus of the study is to present an overview of reduplication in Sinhala mainly with respect to major types and functions associated with this phenomenon. Nevertheless, in the absence of a study on Reduplication in Sinhala, it is expected that the present study will serve some purpose in contributing to the empirical domain and thus will lead to future studies.

\section{METHODOLOGY}

\section{Data and Data Analysis}

Data for the present study consisted of sentences with reduplication types and functions that can be distinguished in Sinhala. A sample of 60 sentences with such reduplication were used. The researcher consulted 05 adult native speakers of Sinhala for their grammaticality judgments about those sentences. Although the researcher himself is a native speaker of Sinhala, still the grammaticality judgments of others were sought for better accuracy. The examples and example sentences given in the following sections are the data used for this purpose and the grammaticality judgments and opinions of native speakers of Sinhala were sought with respect to them.

\section{Sinhala complete reduplication: Nouns}

As discussed in the preceding sections, full or complete reduplication refers to the repetition of the entire word, word stem (root with one or more affixes), or root. 
The above example is a contrastive reduplication which is a form of intensification that is quite common in the language. The repetition indicates that the speaker is intending the most prototypical meaning of the word, as illustrated below.

A: What is there: else/be careful)

B: veeduru-veeduru (glass, nothing

\section{Sinhala complete reduplication: Verbs}

One way of making the present participle of verbs in Sinhala is through reduplication.

(20) bala-bala 'seeing'

$$
\text { (21) Nimal potha bala-bala }
$$

bath kaeva

rice ate

Nimal(Nom) book seeing-seeing

Nimal ate rice while reading the book

To express intensity/to intensify (19).

(22) enna-enna - ' 'come come'

Sinhala complete reduplication: Adjectives.

Adjectives are often reduplicated to intensify the quality/nature expressed by them $(20,21)$.

(23) rasa-rasa dodam Sweet-sweet oranges (very sweet oranges)

(24) punchi-punchi geval Small-small houses (very small houses)

Sinhala complete reduplication: Adverbs.

Adverbs are often reduplicated to intensify the degree expressed by them (22).

(25) hemin-hemin
Slowly-slowly (very slowly)

\section{Sinhala partial reduplication: nouns}

As the term suggests, here only a part of the lexical item is repeated. Generally partial reduplication is manifested in a number of forms such as consonant gemination, vowel lengthening, or nearly complete copy of a base. As the following examples indicate, partial reduplication in Sinhala is manifested in the repetition of the suffix.

The pluralizing suffix -al is repeated and the resulting compound noun functions as a single lexical item where the leftmost element determines the overall meaning.

26) geval-dorawal

houses-doors (houses)

Although the above compound is compositional, there are reduplicated elements which are non-compositional, as both the elements convey meaning only as a single lexical item $(24,25)$. Morphologically they can be analyzed as 'headless' compounds where none of the elements in the word determine its meaning as in English 'pickpocket' or 'faintheart'. They can also be called 'exocentric' compounds in the sense that they have a 'center' outside themselves (Katamba: ...)

(27) lata-pata - 'knickknack'

(28) val-pal - 'gossip'

Sinhala partial reduplication: verbs

(29) kaala-beela

eat(pp)-drink(pp) (enjoying life)

(30) api hondata kaala-beela innava 
We well eat-drink live

We enjoy life

Sinhala partial reduplication: Adjectives (non-compositional)

$$
\text { sata-kapata 'cunning' }
$$

Sinhala partial reduplication: Adverbs (non-compositional)

(32) jara-bara 'noise of something being crushed'

(33) indala-hitala 'occasionally'

Other functions of Reduplication

\section{Proverb formation}

Sinhala uses extensive uses of reduplication to make proverbs. In such cases, the verbal element is iterated. The form of the verb depends on the intended meaning and often the iteration adds a rhythmic effect.

(34) kala kala de pala pala
de
do(adj) do (adj) things effect effect
things

'Your actions will determine the consequences' (negative effect)

$$
\begin{aligned}
& \text { Gahanna Gahanna } \quad \text { vandina } \\
& \text { miniha moodaya }
\end{aligned}
$$

Hit(Inf) hit(Inf) worship(adj) man fool

'the man who tolerates being beaten many times is a fool'

\section{Expressives}

By far the most common and extensive use of reduplication in Sinhala can be observed in the formation of expressives. This corresponds to the imitations of different sounds of nature, sounds made by animals, and thus fall within the traditional conception of onomatopoeia/echo formations. Once again, both full and partial reduplication can be observed. The reduplicated element functions as a single lexical item and therefore is noncompositional.

Full Reduplication

(36) kaak - kaak 'crow's noise /cawing'

(37) gudu - gudu 'drinking sound'

(38) haka-haka "laughing sound'

All the above have an adverbial function.

Partial Reduplication: here the second/final syllable is repeated (36).

(39) dadi-bidi 'sound of interchange of blows or of the falling of some heavy things in succession'. But in its actual use, it means doing something quickly/hurriedly and hence conveys an adverbial function (37).

(40) mama dadi-bidi gaala naegitta

I(Nom) dadi-bidi like got up

'I got up quickly'

\section{RESULTS AND DISCUSSION}

This study aimed to explore the reduplication phenomenon in Sinhala in the broader context of reduplication patterns and functions manifested in the world's languages. It sought to answer a number of research questions and the following sections attempt to answer those. 
(a) What are the reduplication types manifested in Sinhala?

As the above data indicated, two broader types of reduplication can be observed: full and partial. Both contribute significantly to the word formation and expressive range of Sinhala. Full reduplication results in the formation of compound words which are compositional as well as non-compositional with respect to their semantic properties. Within these two broad types, further finegrained sub classes are not manifested.

(b) What categories or linguistic elements are affected by this process? / In what areas of language is reduplication manifested?

Reduplication can be observed in all four major word classes: nouns, verbs, adjectives, and adverbs in Sinhala. The process occurs both as full and partial. However, their distribution with respect to each other is not uniform. For example, in the case of complete reduplication, verbs are the most reduplicated elements, whereas nouns are the least. At the level of partial reduplication, adverbs are the most reduplicated elements.

c) What are the functions of reduplication?

The most notable grammatical function reduplication fulfills in Sinhala is the present participle formation which can be subsumed under aspect marking. The root form of most of the transitive verbs can be reduplicated to form the present participle. However, this form cannot occur on its own. Rather it should occur with a main verb and hence, is quite similar to the English infinitive where only PRO can occur (38), (39).

(41) Nimali

[PROi koopi bi-bii] potha baeluwa
Nimal(Nom) [PRO coffee drinking-drinking] book read

'Nimal read the book while drinking coffee'

(42) Nimali tried [PROi to leave]

The functions associated with reduplication in Sinhala are limited when compared to many other languages discussed in the preceding sections. In addition to the present participle formation, other common functions are the derivation of manner adverbials and expressives. A limited number of them also function as intensifiers. In terms of word formation, what we can see mostly is the derivation of compound words. Yet, derivation of totally new words as in Indonesian "bantal -'pillow' > bantalbantal 'railway tie' is absent.

d) Where does Sinhala fit in a typology of reduplication?

Though reduplication in Sinhala is a pervasive phenomenon, its range is quite limited in terms of both types/sub-types and functions. Of the feasible types, less grammatical distinctions and more semantic distinctions can be observed. The following table presents the Sinhala facts in relation to the other languages we discussed in the preceding sections. 
Table 1: Typology of Sinhala Reduplication

\begin{tabular}{|c|c|c|c|}
\hline Language: Sinhala & Presence & Example languages: & Presence \\
\hline $\begin{array}{l}\text { 1.Formation of totally new } \\
\text { words }\end{array}$ & No & Indonesian & Yes \\
\hline 2.Marking of plurality & No & Papago (Uto-Aztecan, USA) & Yes \\
\hline 3. Marking of aspect & Yes & Alabama & Yes \\
\hline $\begin{array}{l}\text { 4. Number (collectives, } \\
\text { distributives, limitatives) }\end{array}$ & No & $\begin{array}{lll}\text { Santali, } & \text { Pangasinan, Ao } \\
\text { Naga } & \end{array}$ & Yes \\
\hline $\begin{array}{l}\text { 5. Inchoative (to mark } \\
\text { beginning of verbal action) }\end{array}$ & No & Till (Salish) & Yes \\
\hline 6. Attenuation & No & Tigre (Semitic, Eritrea) & Yes \\
\hline 7. Intensity & Yes & $\begin{array}{lll}\text { Arapesh } & \text { (Papua } & \text { New } \\
\text { Guinea) } & & \end{array}$ & Yes \\
\hline 8. Transitivity & No & Fijian & Yes \\
\hline 9. Conditionality & No & Luiseno & Yes \\
\hline 10. Case & No & Chukchi (Russia) & $\begin{array}{l}\text { Yes } \\
\text { (Absolutive) }\end{array}$ \\
\hline 11. Proverb formation & Yes & Languages shown here & No \\
\hline $\begin{array}{l}\text { 12. Formation of lexical } \\
\text { subclasses (comparative degree } \\
\text { marking) }\end{array}$ & No & Ilocano & Yes \\
\hline 13. Diminutive & No & Tuvan (Altaic, Siberia) & Yes \\
\hline 14. Altering of word class & Yes & Kayardild (Pama Nyungan) & Yes \\
\hline $\begin{array}{l}\text { 15. Meaning } \\
\text { extension/inclusive function }\end{array}$ & Yes & Tamil, Kannada, Bengali & Yes \\
\hline 16. Pretense & No & Ilokano & Yes \\
\hline
\end{tabular}


As shown in the table, Sinhala reduplication is limited to only 05 of the 16 properties listed above. Nevertheless, the proverbial formation seems to be unique to Sinhala. Overall, Sinhala is quite impoverished in a typology of reduplication.

In terms of where reduplication occurs, Sinhala displays all full reduplication types manifested in other languages. They are reduplication of the entire word, stem (root with one or more affixes), or root. As for partial reduplication, world's languages show a number of forms such as consonant germination, vowel lengthening, or the reduplicated material can be partial root, simple root, or a partial stem as in Ilocano (Austronesian, Philippines). In Sinhala, however, this range is quite limited. In most of the languages with partial reduplication, reduplicated material is most often found at the beginning of a base (with medial and final positions too as other possibilities). Yet, quite interestingly in Sinhala partial reduplication, the reduplicated material is found only at the final position. This can be seen as copying of the entire base except the initial consonant-vowel (CV) which is replaced by another consonant-vowel of the reduplicant. This patterns with Tuvan (Altaic, Siberia) as in pelek 'gift' pelekselek 'gift- DIMINUTIVE, or as in Tamil puli 'tiger' $>$ puli-kili 'tigers and other beasts' where the initial $\mathrm{CV}$ of the reduplicated material is replaced by ki. These are generally termed as echo constructions. Complex reduplication patterns with some vowel or consonant change in the medial position, or phoneme alteration as we notice in some other languages are not available in Sinhala. What is available can be termed as simple reduplication of a base/stem/suffix.

\section{CONCLUSIONS}

The aim of this paper was to explore the reduplication phenomenon in Sinhala in a general typology of reduplication manifested in the world's languages. As the preceding data and the discussion show, Sinhala is quite impoverished when viewed against the broader spectrum of reduplication types, sub-types, functions, and even in the areas of language affected by reduplication. The author did not wish to analyze the data presented in relation to a particular theoretical standpoint mainly because such standpoints abound. However, such a study will be quite useful in the absence of sufficient studies in this area with respect to Sinhala language, and can be the focus of a future study by a prospective researcher. The answers to the research questions highlight that despite reduplication being a pervasive phenomenon in Sinhala, the extent of its application is limited mostly to echoformations. As for grammatical functions, present participle aspect marking was the only grammatical function it fulfills in Sinhala.

\section{REFERENCES}

Ananda, L.(2012). Clausal complementation in Sinhala. Unpublished $\mathrm{PhD}$ thesis, Jawaharlal Nehru University.

Ananda, L., Prabath, K. (2016).Configurationality and mental grammars; sentences in Sinhala with reduplicated expressions. International Journal of Multidisciplinary Studies, 3(2), pp. 25-34.

Rubino, C. (2005).Redplication: Form, function and distribution. In: Bernhard 
Hurch, editor. Studies on Reduplication. Berlin: Mouton de Gruyterp, pp.11-30.

Jill ,Carrier-Duncan.(1984). Some problems with prosodic accounts of reduplication. In: Mark Aronoff, Richard Oehrle, editors. Language sound structure. Cambridge, MA: MIT Press; pp. 260-86.

Gil ,David.(2005). From repetition to reduplication in Riau Indonesian. In: Bernhard Hurch, editor. Studies on Reduplication. Berlin: Mouton de Gruyter, pp. 31-64.

Robert, Dixon M.W.( 1998). A Grammar of Boumaa Fijian. Chicago, University of Chicago Press.

Keane ,Elinor. (2005).Phrasal Reduplication and Dual Description. In: Bernhard Hurch, editor. Studies on Reduplication. Berlin: Mouton de Gruyter, pp. 239-262.

Raimy, Eric. (2000). The Phonology and Morphology of Reduplication. Berlin: Mouton de Gruyter.

Gair, J.W. (1998). Studies in South Asian linguistics: Sinhala and other South Asian languages. Selected and edited by Barbara C. Lust. New York \& Oxford: Oxford University Press.
Hagstrom, P.A.( 1993). Decomposing questions. Doctoral dissertation, MIT.

Haspelmath ,Martin.( 2002). Understanding Morphology. London:Arnold.

Henadeerage ,D.K.( 2002). Topics in Sinhala syntax. Doctoral dissertation, Australian National University.

Kariyakarawana ,S .M.( 1998). The Syntax of Focus and WH Questions in Sinhala. Colombo: Karunaratne and Sons LTD.

Karunatillake, W.S.( 1992). An introduction to spoken Sinhala. Colombo: Gunasena \& Company Limited.

Marantz ,Alec.( 1982). Re reduplication. Linguistic Inquiry, 13,pp. 483-545.

Mccarthy, J and Alan ,P. (1995).Faithfulness and reduplicative identity. In: Jill Beckman, Laura Dickey, Suzanne Urbanczyk, editors. University of Massachusetts Occasional Papers in Linguistics 18: Papers in Optimality Theory. Amherst, MA: GLSA, pp. 249-384.

Moravcsik, E. (1978). Reduplicative constructions. In: Joseph Greenberg, editor. Universals of human language. Stanford: Stanford University Press, pp. 297-334. 
Newman, Paul. (2000). The Hausa Kouwenberg ,Silvia and Lacharite ,Darlene. language: an encyclopedic reference (2005). Less is more: Evidence from grammar. New Haven: Yale University diminutive reduplication in Caribbean Press; Creole languages. In: Bernhard Hurch, editor. Studies on Reduplication. Berlin: Mouton de Gruyter, pp. 533-546.

Palmer, F.R.( 1981). Semantics. Cambridge: Cambridge University Press.

Raimy, Eric.( 2000). The phonology and Donca , Steriade.( 1988). Reduplication and syllable transfer in Sanskrit. Phonology, 5, pp. 73-155.

morphology of reduplication. Berlin: Mouton.

Singh ,Rajendra. (2005). Reduplication in Maas, Utz.( 2005). Syntactic Reduplication in Arabic. In: Bernhard Hurch, editor. Studies on Reduplication. Berlin: Mouton de Modern Hindi and the Theory of Gruyter, pp. 395-430.

Reduplication. In: Bernhard Hurch, editor. Studies on Reduplication. Berlin: Mouton de Gruyter, pp. 263-282.

Shibasaki, Reijirou.(2005). On the grammaticalization of verbal reduplication in Japanese. In: Bernhard Hurch, editor. Studies on Reduplication. Berlin: Mouton de Gruyter,pp. 283-314.

Inkelas ,Sharon and Zoll ,Cheryl.( 2009). Reduplication: Doubling in morphology. New York: Cambridge University Press;.

Inkelas Sharon.(2005). Morphological Doubling Theory: Evidence for morphological doubling in reduplication. In: Bernhard Hurch, editor. Studies on Reduplication. Berlin: Mouton de Gruyter, pp. 65-88. 